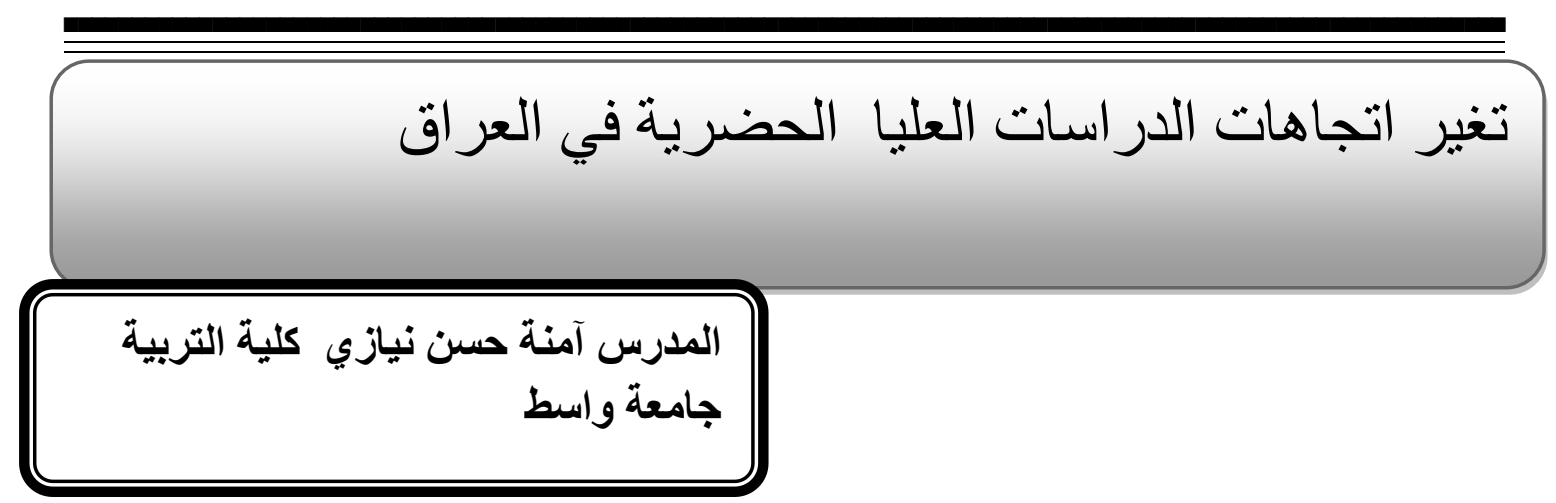

الملخص

يسلط البحث الضوء على اهمية در اسة التغير الكمي والنوعي في اتجاهات الدراسات

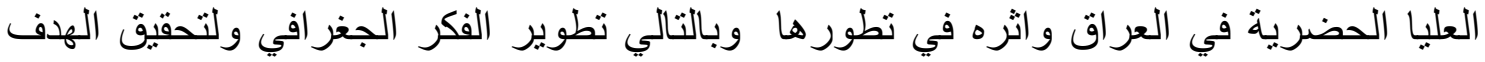

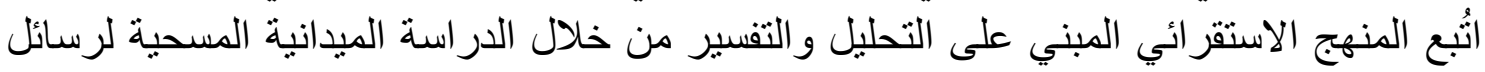

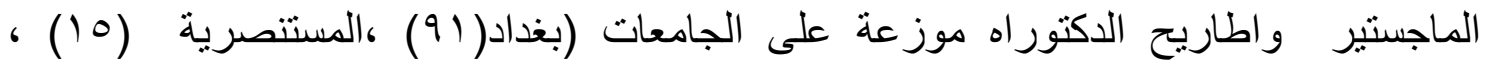

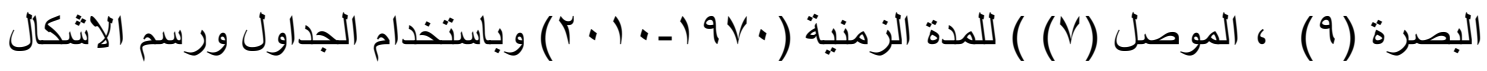
و تفسيروتحليل النتائج توصلت الباحثة الى ما يلي :

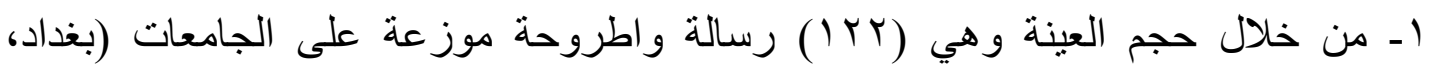

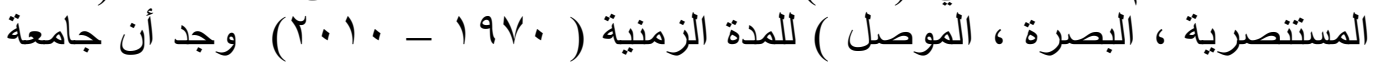

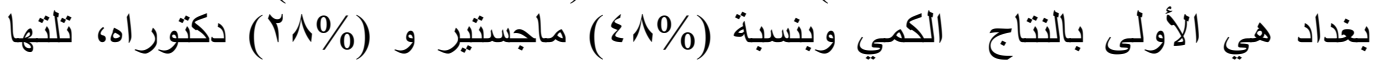

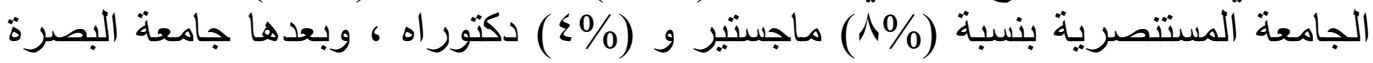

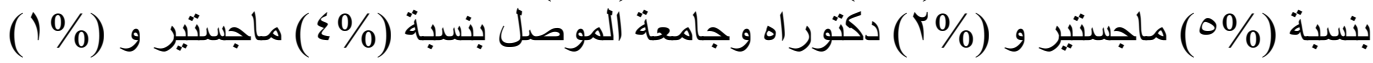
دكتور اه. ץ- وجود تغير نوعي في الدر اسات الحضرية في العراق وكانت جامعة بغداد هي الأولى في الكي

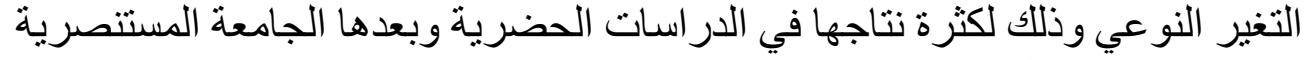

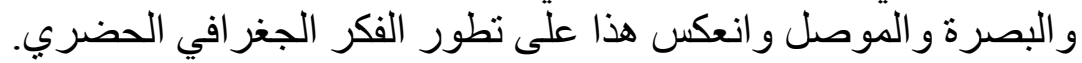

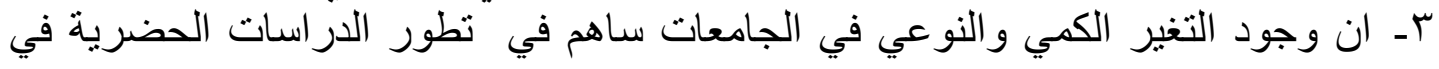

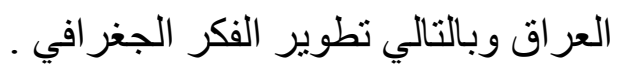

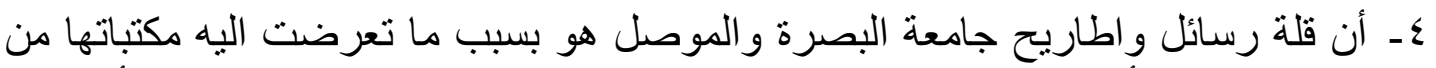

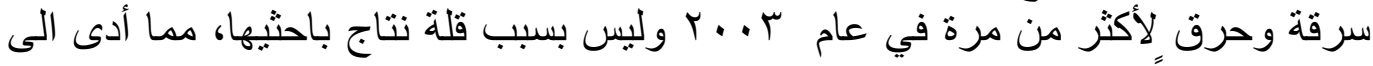
تر اجعها عددياً.

\title{
Abstract
}

The changing in trends of postgraduate studies in urban Geography of Iraq 
The current research highlight on the importance of studying quantitative and qualitative change in trends of postgraduate studies in urban Geography of Iraq and its impact on the development of geographical thought, to achieve this target, It has been followed the inductive method and the philosophical analytical approach that based on the analysis and criticism processes to reach the goals of the research, through field survey for the productions of masters dissertations and doctoral theses of the Urban Studies thesis in Iraq, distributed on the main universities in Iraq as follow :Baghdad University ( 91 study), Mustansiriya University (15 study), Basra University (9 study), and Mosul University (7 study), for the period from $19 \mathrm{~V} \cdot$ to $r \cdot 1 \cdot$.

By using tables and drawing charts that help to interpret and analyse the results, the following conclusions have been achieved:

1- Through the sample size, which is (122) masters dissertations and doctoral theses distributed on the main universities (Baghdad, Mustansiriya, Basra, Mosul) for a period of time (from 1970 to 2010), It have been found that the University of Baghdad, is the first quantitative of productive rates with a percentage (48\%) Master's and (28\%) Ph.D., followed by the University of Mustansiriya by (8\%) Master and (4\%) PhD, and then the University of Basra (5\%) Master and (2\%) PhD and the University of Mosul (4\%) Master and (1\%) PhD.

$r$ - There are qualitative changes in urban studies in Iraq and the Baghdad University is the first in a qualitative change due to the large number of its productions in urban studies, and then the University of Mustansiriya, Basra and Mosul, where that was reflected on the evolution of urban geographical thought.

$r$ - The presence of quantitative and qualitative changes in the universities contributed to develop of urban studies in Iraq and thus the development of geographical thought studies.

\&- the main reason of the limitation in the productions of theses and dissertations in both Basra and Mosul Universities are because of what has happened from stealing and burned their libraries many times.in 2003 And not because of the productivity of its researchers, which led to the decline the scientific productivity

اصبحت الدراسات الحضرية بمفوهمها الواسع مثار اهتمام الباحثين من فروع علمية مختلفة

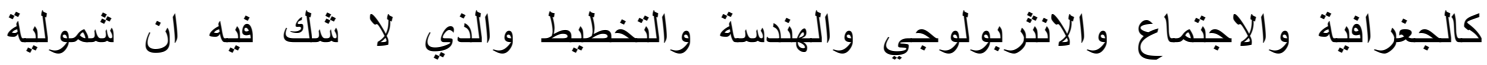

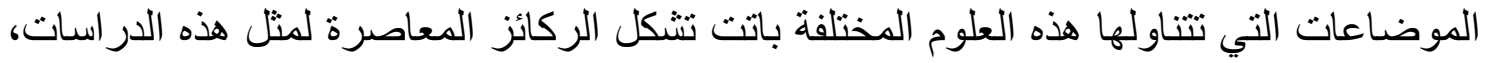

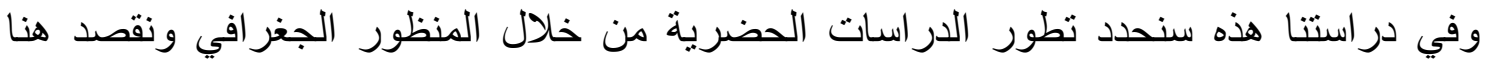
بالدراسات الحضرية هي جغر افية المدن احد فروع الجغر افية ولاهمية هذا الفرع وذللك لارنباطه 
بالمدينة وبالتالي انعكاسه على الانسان الذي يعيش فيها ، فلابد من دراسة تطور تلاك الدر اسات

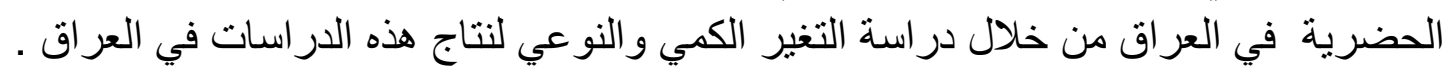
مشكلة البحث : تتمثل في هل يوجد تغير كمي ونوعي للار اسات الحضرية في العراق اثر في تطور ها

فرضية البحث : نظر الطول المدة الزمنية للار اسة فلابد من وجود تغير كمي ونوعي للدراسات الحضرية في العراق و الذي بدوره اثر في تطور در استها في العراق .

هدف البحث : هو تطوير الدراسات الحضرية في العراق كما ونو عا للارتقاء بها الى الافضل . حدود البحث : وهي الحدود الموضوعية متمثلة بنتاج رسائل واطاريح الجامعات والحدود

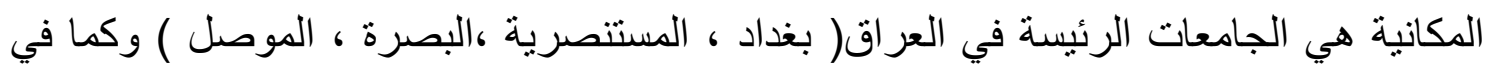

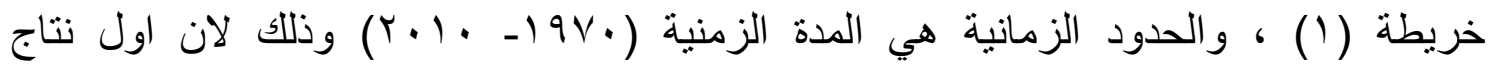

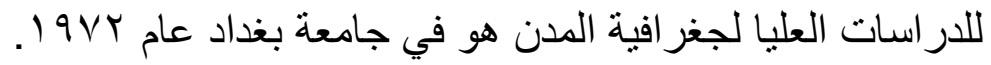
الارسات السابقة : لاتوجد در اسات سابقة لمثل هذه الدر اسة وهذا هو مبرر الدراسة . منهج البحث وطريقته : اتبعت الباحثة المنهج الاستقرائي المبني على التحليل والتفسير للوصول الى هدف البحث واقتضى البحث استخدام طريقة الدراسة المبدانية المسحية لرسائل واطاريح

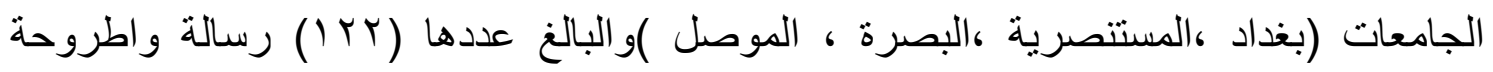

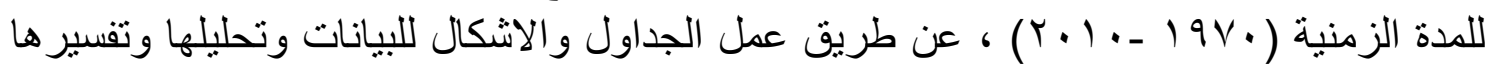
للوصول الى النتائج .

وقسم البحث الى اربعة اقسام رئيسة وهي اولا تطور الدراسات الحضرية وثانيا التغير الكمي

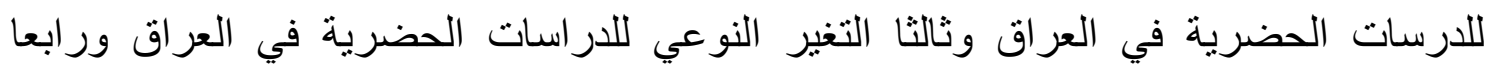
الاستنتاجات و التوصيات. 
خريطة (1) الحدود المكانية للار اسة

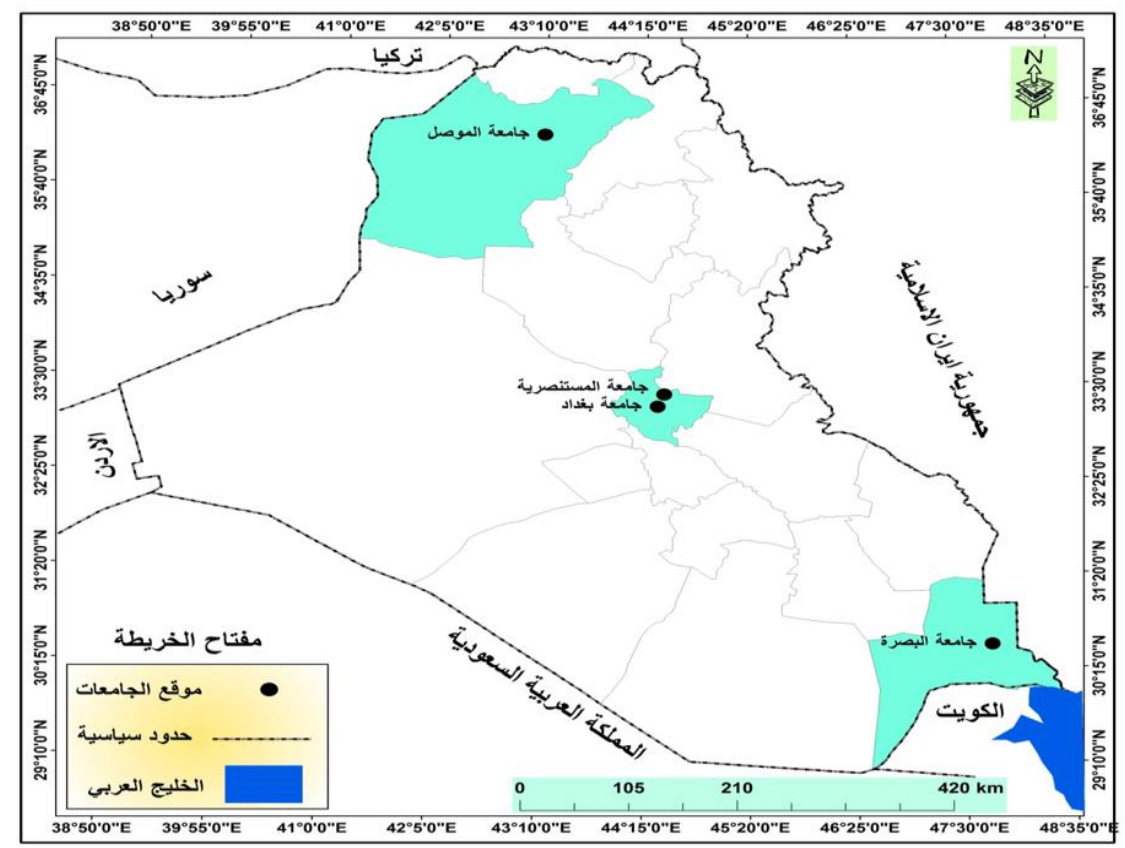

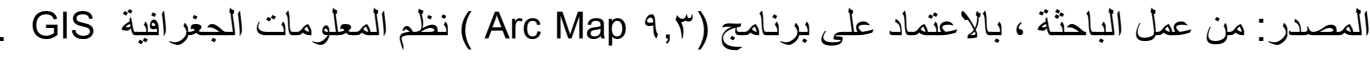

$$
\text { أولا: تطور الاراسات الحضرية :- }
$$

تعنى الدر اسات الحضرية من المنظور الجغر افي بدر اسة المدن، واهتمام الجغر افي بالخصائص الحضرية للمدن ليس جديداً وانما يعود الى ايام الأغريق و الرومان والرحالة العرب الذين الذين برزوا

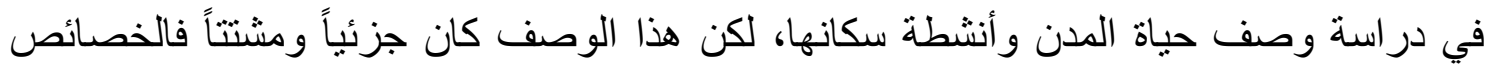

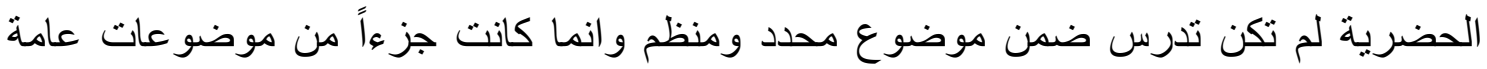
تناولتها الجغرافية ولهذا فان ظهور ما يعرف بجغرافية الحضر ( Urban Geography ) كموضوع اكاديمي مستقل ظاهرة حديثة نسبياً'(') و أختلف الباحثون الجغر افيون في استخدام

(') عبد الاله ابو عياش، اسحق يعقوب القطب، الاتجاهات المعاصرة في الدراسات الحضرية، طا، الكويت، 191 19. ص10. 
جغر افية الحضر فهنالك من ربطها بجغرافية المدن(r) و اطلق عليها البعض جغر افية العمران(؟)

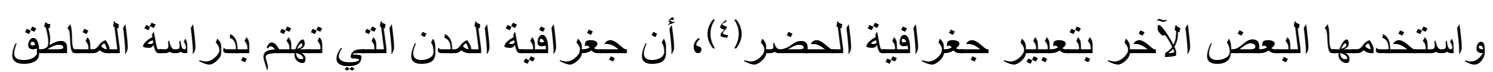

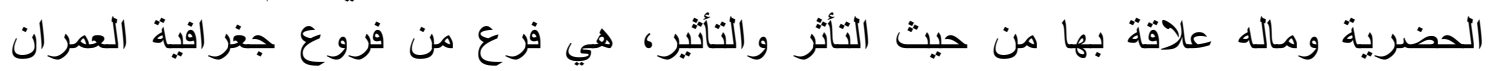
Geography of settlement

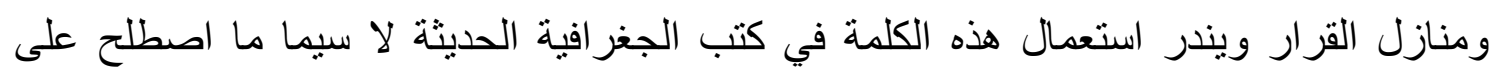

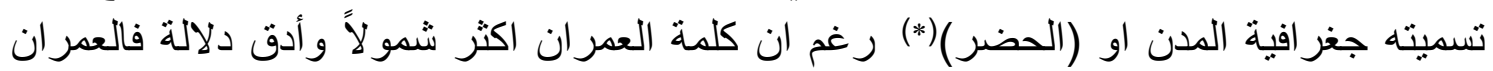

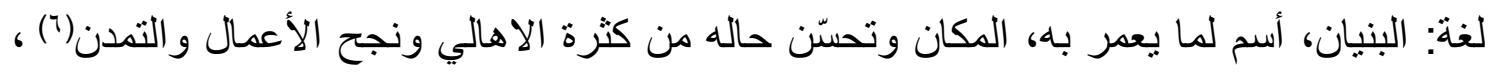

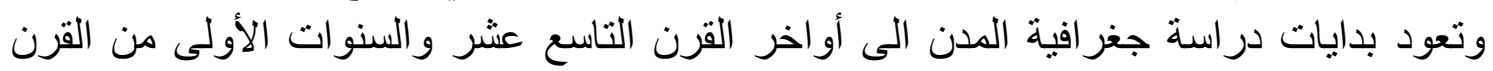

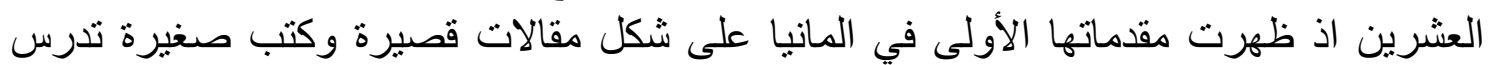

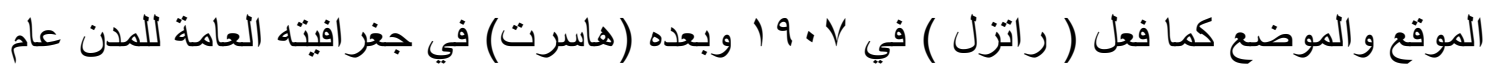

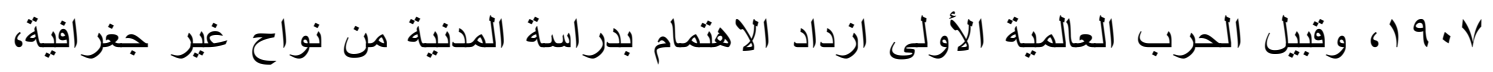

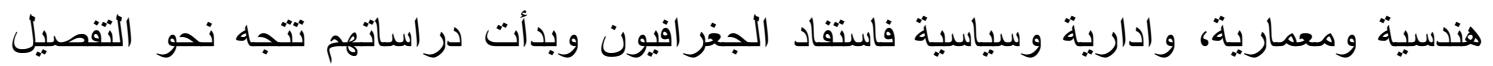

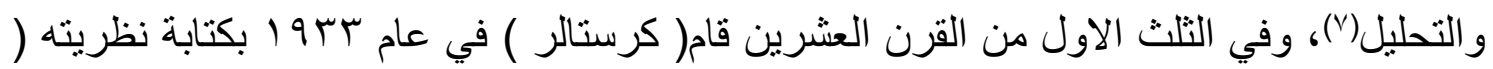
الاماكن المركزية) والتي عُدت فتحاً منهجياً في تناوله لظاهرة المدنية من حيث الاحاطة التامة

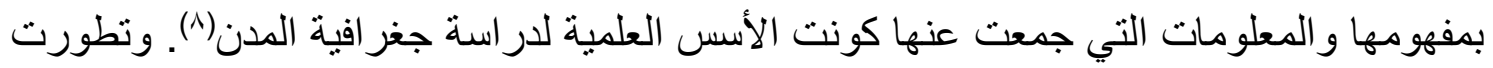
جغر افية المدن بشكل تدريجي في النصف الاول من القرن العشرين واعتمد هذا التطور على التى

(") جمال حمدان ، جغرافية المدن، طץ، القاهرة، 9 ( 19 ، صهـ.

(") عبد القتاح محمد وهيبة، جغرافية العمران، منشأة المعارف الإسكندرية، الإسكندرية ، ه و 19، ص • 1.

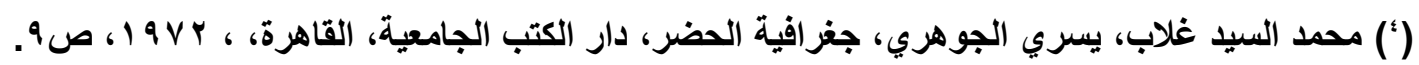

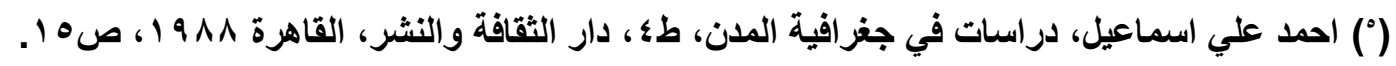

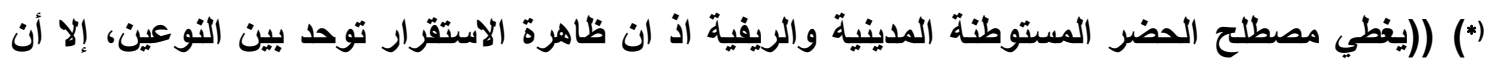

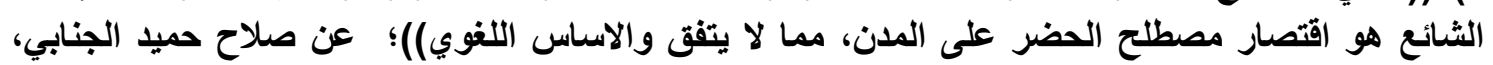

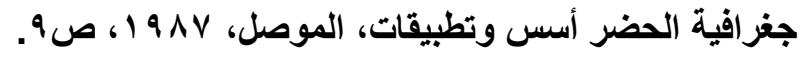
(") لويس معلوف، المنجد في اللغة ، المطبعة الكاثولوكية، ط9 1، بيروت، 979 19، ص99 به. (l) (القتاح محمد وهيبة، مصدر سابق، ص • (1) ( ) محمد السيد غلاب، يسري الجوهري، مصدر سابق، صلَ. 
العديد من المفاهيم الاساسية التي وضعها عدد محدد من العلماء، ففي عام · ع 1 ظهرت أولى الحلقات الدراسية في جغرافية المدن من قبل ( هيرس ) Chauncy Harris و (أدورد المن) Edward Ullman النصف الثاني من القرن العشرين بانقسامها الى تخصصات كجغر افية المؤانى التي برز فيها

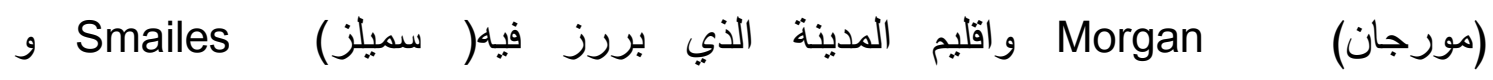
Mumford وتخطيط المدينة ونشأتها الذي اشتهر فيه (ممفورد) Dickinson(دكنسون) و ودكنسون ) و هي اليوم تهتم بدر اسة اقاليم المدن وشكلها وتركيبها ووظائفها وسكانها (·) . وقد سبق العرب غيرهم في دراسة جغر افية المدن من حيث وصفها ووصف اقاليمها

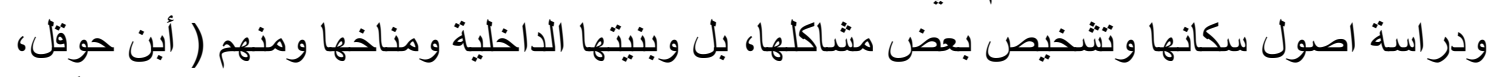

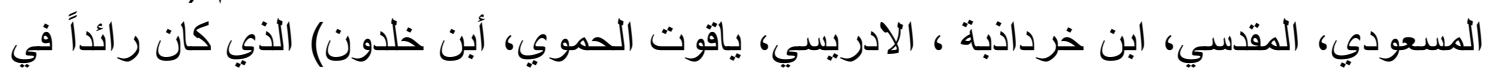

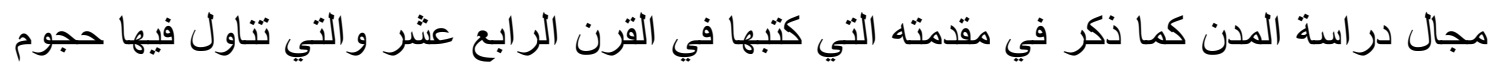

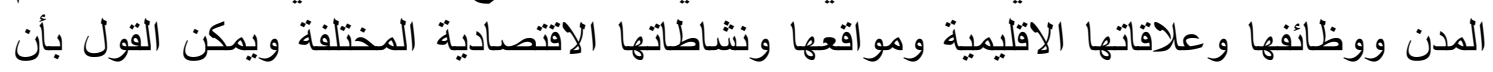

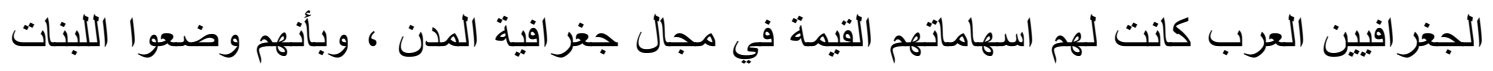

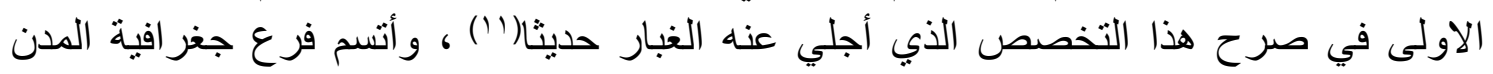

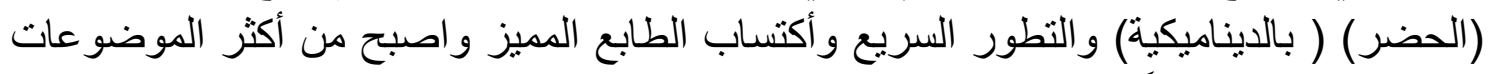

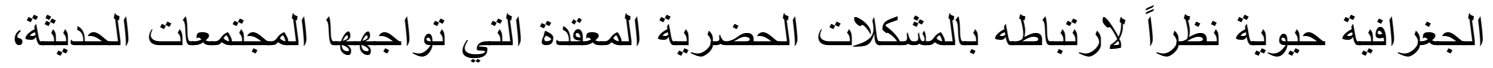

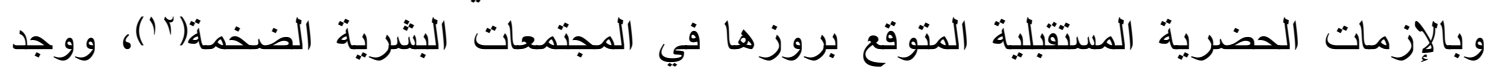

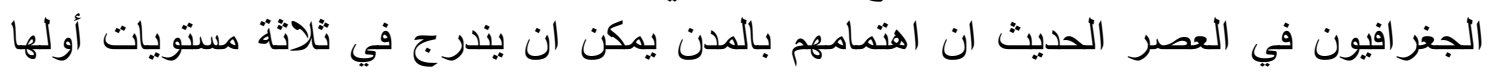

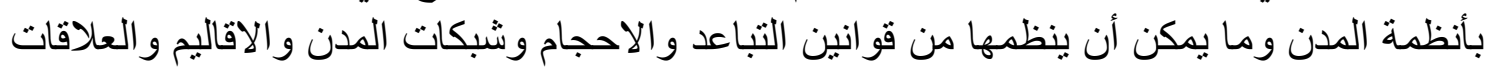

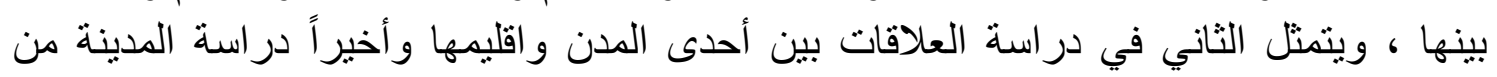

)`( David Kaplan, James Wheeler and Steven Hollway, Urban Geography, United States of America, rsd ed r...q, P-q.

$$
\begin{aligned}
& \text { (') عبد الله عطوي ، جغرافية المدن ، ج (،دار النهضة العربية ـ بيروت ـ لبنان ، I . . Y، صVV. } \\
& \text { (") صبري فارس الهيتي ، جغرافية المدن ،طا ،دار صفاء، عمان ، • 1 r، صب ا. } \\
& \text { (") (بل الاله ابو عياش، اسحق القطب، مصدر سابق، ص17 } 1 . \\
& \text { 佮 Y r }
\end{aligned}
$$


الداخل من حيث الموضع و التركيب والنمو و الوظائف وتفاعل ذللك كله في خدمة الانسان، ساكن

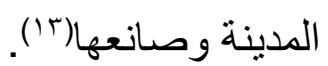
وابرز طرق البحث في جغر افية المدن هي :

ا ـ الطريقة الوظيفية:- إذ يؤكد فيها الجغر افي على دراسة توزيع المدن وحجومها وتباعدها

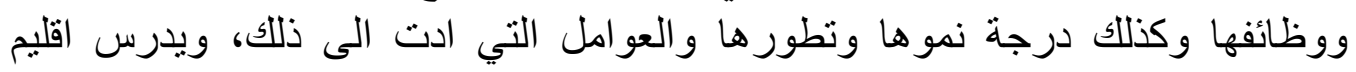

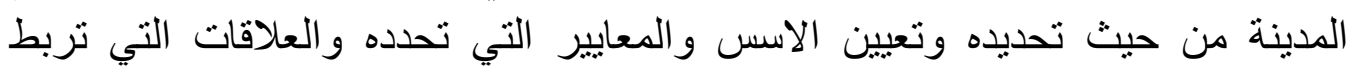
المدينة بالإقليم و العلاقات بين اقليم و اقليم

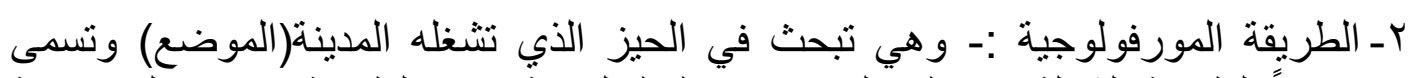

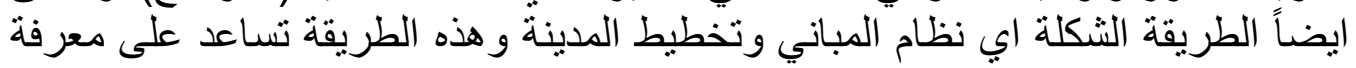

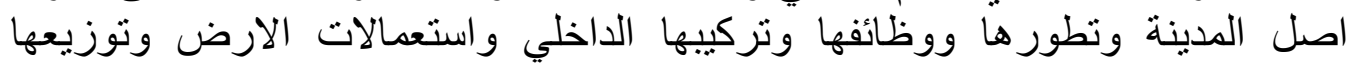

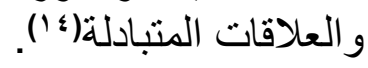
ومن الطرق التفصيلية الخاصة بلدر اسة موضو عات جغر افية المدن هي:-

ا - در اسة وظائف المدن من حيث تركيبها الداخلي وتتظيمها واحو ال سكانها وكيفية تخطيطها وتقسيمها الى مناطق او اقاليم وظيفية منل منطقة الاعمال المركزية)(CBD) و المنطقة السكنية و المنطقة الصناعية و غير ها. ؟- در اسة التطور التاريخي للمدينة و الاهتمام بنمو فعالياتها و العو امل التي اثرت في شكلها وتركيبها على فترات ذللك النشوء و التطور (10). بـ در اسة العلاقات التي تربط المدينة بإقليمها او منطقة نفوذها وهي البحوث التي تتطلب الالمام بالطرق الاحصائية والتعبير عنها بالأشكال و الخر ائط التي توضئح طبيعة الارتباط بين المدينة و اقليمها.

(") احمد علي اسماعيل، مصدر سابق، ص1 ال.

(') محسن عبد الصاحب المظفر، عر الهاشمي يوسف ، جغرافية المدن مبادئ وأسس ومنهج ونظريات

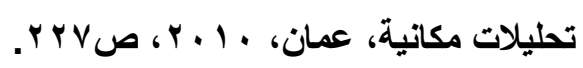

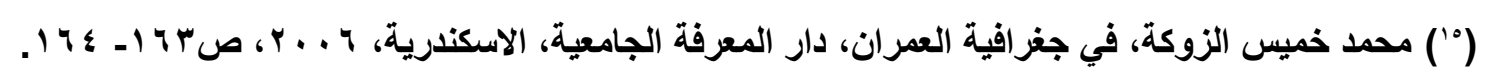


ع - در اسة المدينة كظاهرة اقتصادية ويحاول الجغر افي تحليل نشاطها الى فعاليات اساسية وفعاليات غير اساسية او خدمات والفعاليات الاساسية هي التي تساعد على ولى

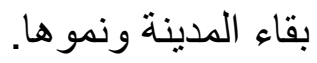

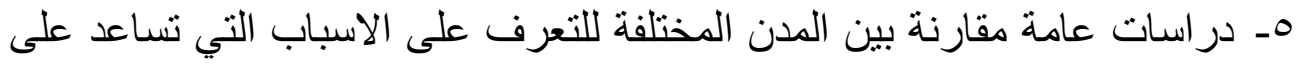
تشابه بعض المدن او اختلاف بعضها عن البعض الاخر (1').

أن الهدف الرئيس في استعر اض هذه المقدمة هو الدخول الى تطور در اسة جغر افية المدن

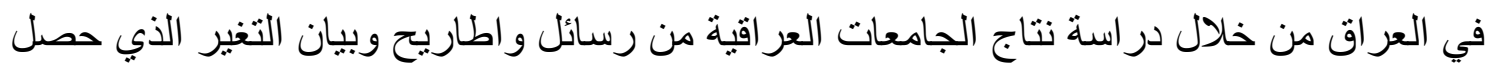

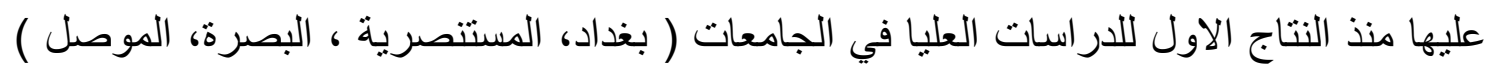

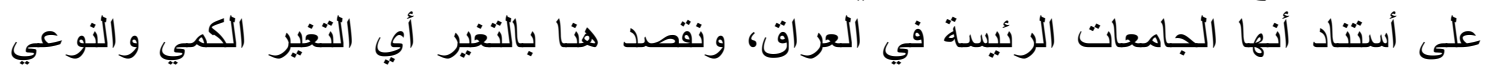

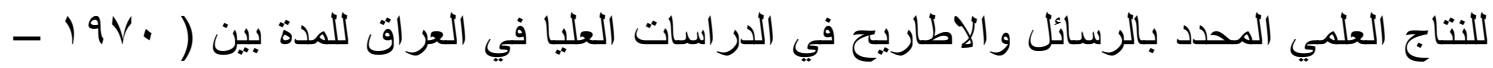

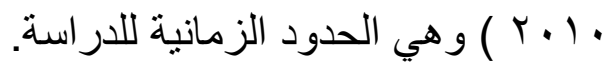

ثانيا:- التغير الكمي للار اسات الحضرية في العراق

من خلال أطلاعنا على الرسائل و الإطاريح الجامعية الخاصة بجغر افية المدن المنتجة في

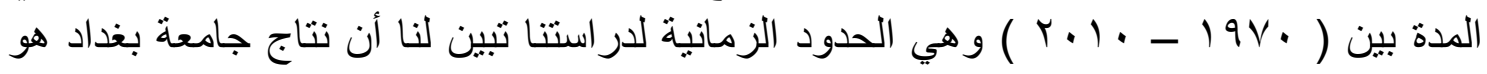

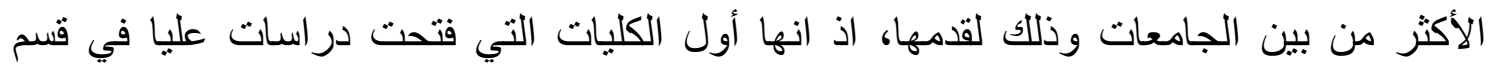

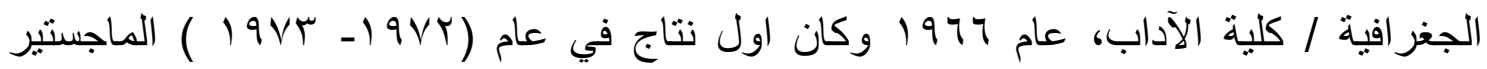

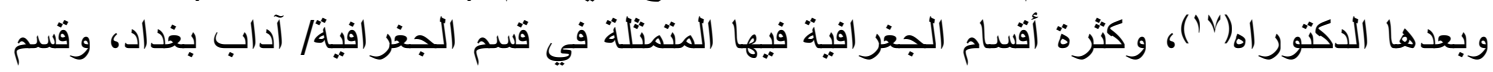

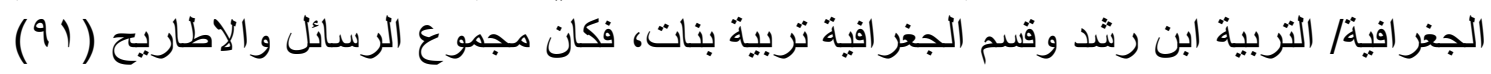

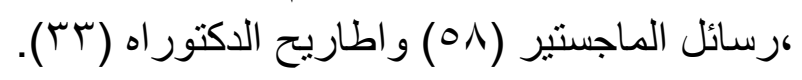

أما الجامعة المستتصرية فقد بلغ نتاجها للار اسات العليا (10) ، الماجستير منها(· (1) و الدكتور اه (0) اذ فتحت فيها الدراسات العليا الدكتوراه في عام ( ب99 19941 ) وبعدها

(") (") 
الماجستير في عام (199v - 1991 ) في كلية التربية قسم الجغر افية(1)، وجامعة البصرة(9) الماجستير منها (V) و الدكتور اه(Y) وفتحت الدراسات العليا في عام ( 1911 - 1919) الماجستير وفي العام الدر اسي (1991 _ 1994 (199) الدكتور اه في كلية الآداب/ قسم الجغر افية(19).

أما جامعة الموصل فقد بلغ نتاجها (V) الماجستير منها (T) و الدكتور اه ( ( ) ، اذ انها فتحت در اسات عليا في كلية التربية /قسم الجغر افية في العام الدراسي (910 1 ـ ـ1911) الماجستير، وفي

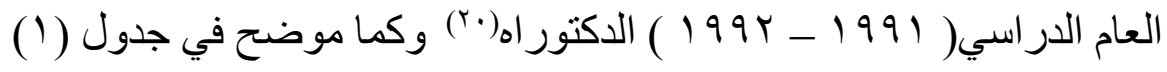

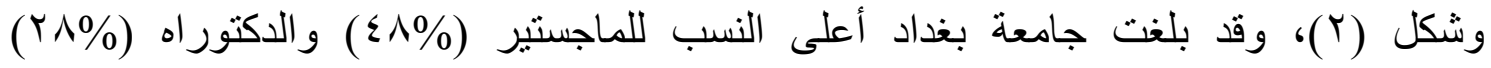
و المستتصرية(^\%)، و الدكتور اه (\%) )، والبصرة الماجستير( \%) و الدكتور اه (Y\%) و الموصل الماجستير( \% §) و الدكتور اه (\%) (1)، ونلاحظ قلة انتاج جامعة البصرة و الموصل من رسائل و اطاريح و هذا لا يعني أنه لا يوجد نتاج و أنما يوجد نتاج ولكن بسبب الظرف الذي تعرض أليه البلد بعد عام r . . r من حرق للمكتبات وسلب للنتاجات العلمية وتخريب أكثر من مرة جعلها تتر اجع عددياً لهذا الحد، وكما موضح في شكل (1) الذي يبين النسب المئوية لنتاج الجامعات من

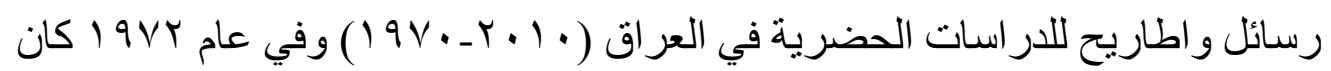

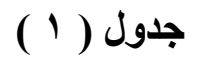

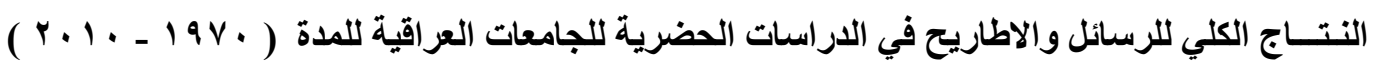

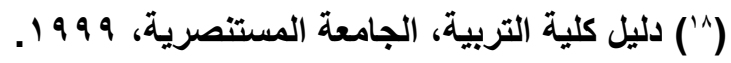

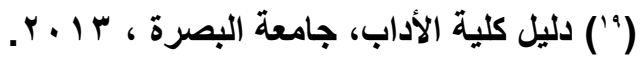

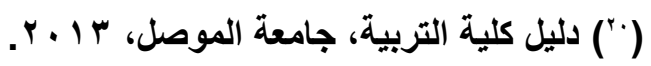




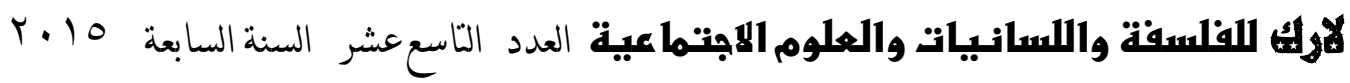

\begin{tabular}{|c|c|c|c|c|c|c|c|c|}
\hline \multicolumn{2}{|c|}{ جامعة البصرة } & \multicolumn{2}{|c|}{ جامعة الموصل } & \multicolumn{2}{|c|}{ الجامعة المستتصرية } & \multicolumn{2}{|c|}{ الاداب+ابن رشد+تربية بنات بغداد } & \multirow[t]{2}{*}{ السنة } \\
\hline الاكتوراه & الماجستير & الدكتوراه & الماجستير & الاكتوراه & الماجستير & الادكتوراه & الماجستير & \\
\hline$\cdot$ & - & $\cdot$ & ? & - & $\cdot$ & ? & $\cdot$ & 198. \\
\hline$\cdot$ & . & . & $\cdot$ & $\cdot$ & $\cdot$ & $\cdot$ & $\cdot$ & $19 V 1$ \\
\hline$\cdot$ & - & - & . & $\cdot$ & $\cdot$ & . & 1 & I9VY \\
\hline$\cdot$ & - & $\cdot$ & $\cdot$ & - & $\cdot$ & . & $r$ & $19 V \%$ \\
\hline$\cdot$ & $\cdot$ & $\cdot$ & $\cdot$ & $\cdot$ & $\cdot$ & $\cdot$ & $r$ & $19 \vee \varepsilon$ \\
\hline . & · & · & $\cdot$ & $\cdot$ & $\cdot$ & $\cdot$ & $\cdot$ & $19 \vee 0$ \\
\hline · & $\cdot$ & $\cdot$ & $\cdot$ & . & $\cdot$ & 1 & $r$ & $19 \vee 7$ \\
\hline$\cdot$ & $\cdot$ & $\cdot$ & . & - & . & 1 & . & $198 \mathrm{~V}$ \\
\hline$\cdot$ & $\cdot$ & $\cdot$ & . & $\cdot$ & . & - & $\cdot$ & $19 \vee \wedge$ \\
\hline$\cdot$ & $\cdot$ & · & · & $\cdot$ & $\cdot$ & $\cdot$ & · & $19 \times 9$ \\
\hline$\cdot$ & . & . & $\cdot$ & - & $\cdot$ & · & $\cdot$ & 191. \\
\hline . & . & . & . & . & $\cdot$ & . & 1 & 1911 \\
\hline . & · & . & . & . & . & . & 1 & $191 \mathrm{r}$ \\
\hline$\cdot$ & - & - & $\cdot$ & . & . & $\cdot$ & 1 & $19 \wedge r$ \\
\hline$\cdot$ & . & . & $\cdot$ & $\cdot$ & $\cdot$ & $\cdot$ & 1 & $19 \Lambda \varepsilon$ \\
\hline$\cdot$ & - & - & $\cdot$ & - & . & . & 1 & 1910 \\
\hline$\cdot$ & . & . & . & . & $\cdot$ & . & . & 1914 \\
\hline$\cdot$ & $\cdot$ & . & . & . & . & . & 1 & $19 \wedge \mathrm{V}$ \\
\hline$\cdot$ & - & $\cdot$ & . & . & $\cdot$ & $\cdot$ & 1 & 1911 \\
\hline . & $\bar{r}$ & $\cdot$ & $\cdot$ & $\cdot$ & $\cdot$ & $\cdot$ & $\mathrm{V}$ & 1919 \\
\hline$\cdot$ & $\cdot$ & $\cdot$ & 1 & - & . & 1 & 1 & 199. \\
\hline . & 1 & . & . & . & . & $r$ & 1 & 1991 \\
\hline
\end{tabular}




\begin{tabular}{|c|c|c|c|c|c|c|c|c|}
\hline • & $\cdot$ & • & . & • & • & $\cdot$ & 1 & 1994 \\
\hline . & $\cdot$ & . & . & . & . & . & . & 1994 \\
\hline . & $\cdot$ & . & $\cdot$ & . & . & $\cdot$ & . & 199 \& \\
\hline . & $\cdot$ & . & . & 1 & . & $r$ & $r$ & 1990 \\
\hline . & . & . & . & . & . & $r$ & . & 1997 \\
\hline . & $\cdot$ & . & . & . & . & $\varepsilon$ & . & $199 \mathrm{~V}$ \\
\hline - & 1 & . & . & . & . & . & . & 1991 \\
\hline . & $\cdot$ & . & . & $\bar{r}$ & . & $r$ & $r$ & 1999 \\
\hline . & 1 & $\cdot$ & $\cdot$ & . & . & $\cdot$ & $r$ & $r \ldots$ \\
\hline . & 1 & $\cdot$ & $\cdot$ & . & 1 & $\cdot$ & 1 & r.. \\
\hline 1 & $\cdot$ & . & 1 & . & $r$ & . & $r$ & $r \ldots r$ \\
\hline$\cdot$ & $\cdot$ & $\cdot$ & 1 & . &. & 1 & $\bar{r}$ & $r \ldots r$ \\
\hline . & $\cdot$ & . & 1 & . & 1 & 1 & $r$ & r... \\
\hline 1 &. & 1 & $r$ & . & 1 & 1 & 0 & $r \ldots o$ \\
\hline • & $\cdot$ & . & . & 1 & 1 & $r$ & $\wedge$ & r.. \\
\hline . & $\cdot$ & $\cdot$ & . & 1 & . & $\varepsilon$ & 1 & $r \ldots v$ \\
\hline . & $\cdot$ &. & . & . & 1 & 1 & $r$ & $r \ldots \wedge$ \\
\hline . & 1 & . & . & . & 1 & $r$ & $\varepsilon$ & r...q \\
\hline . & $\cdot$ & . & . & . & $r$ & $r$ & . & r.l. \\
\hline r & V & 1 & 7 & 0 & 1. & $r r$ & 01 & \multirow{3}{*}{ لمجموع } \\
\hline & & & & & & & & \\
\hline \multicolumn{8}{|c|}{ IrY } & \\
\hline
\end{tabular}

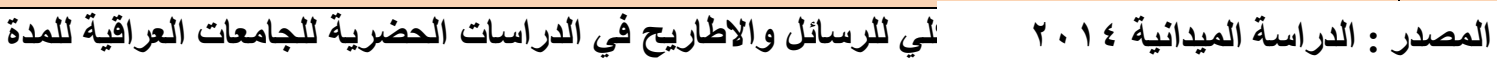

$$
(r \cdot 1 \cdot-19 v \cdot)
$$

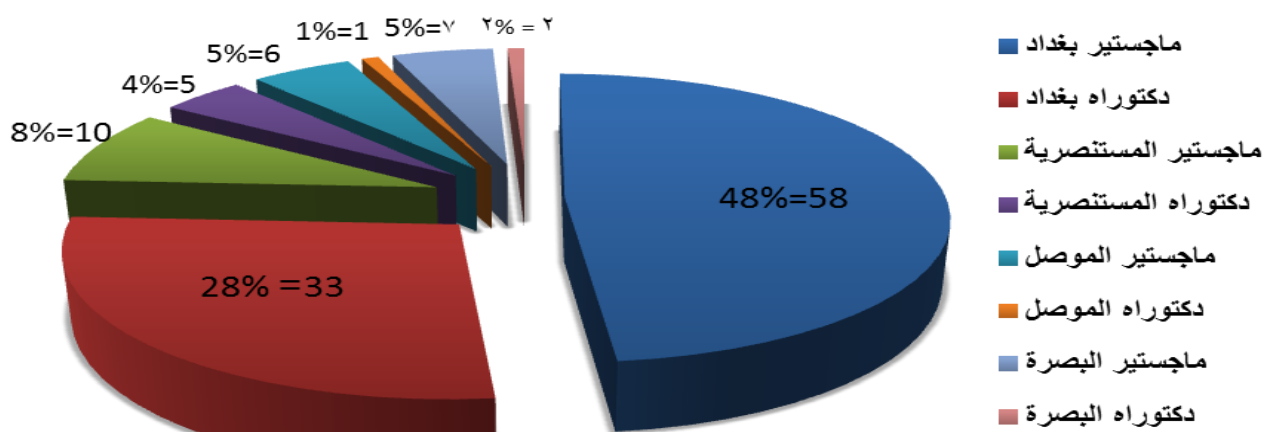


شكل (r)

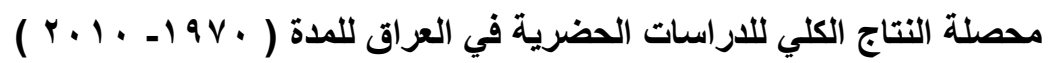

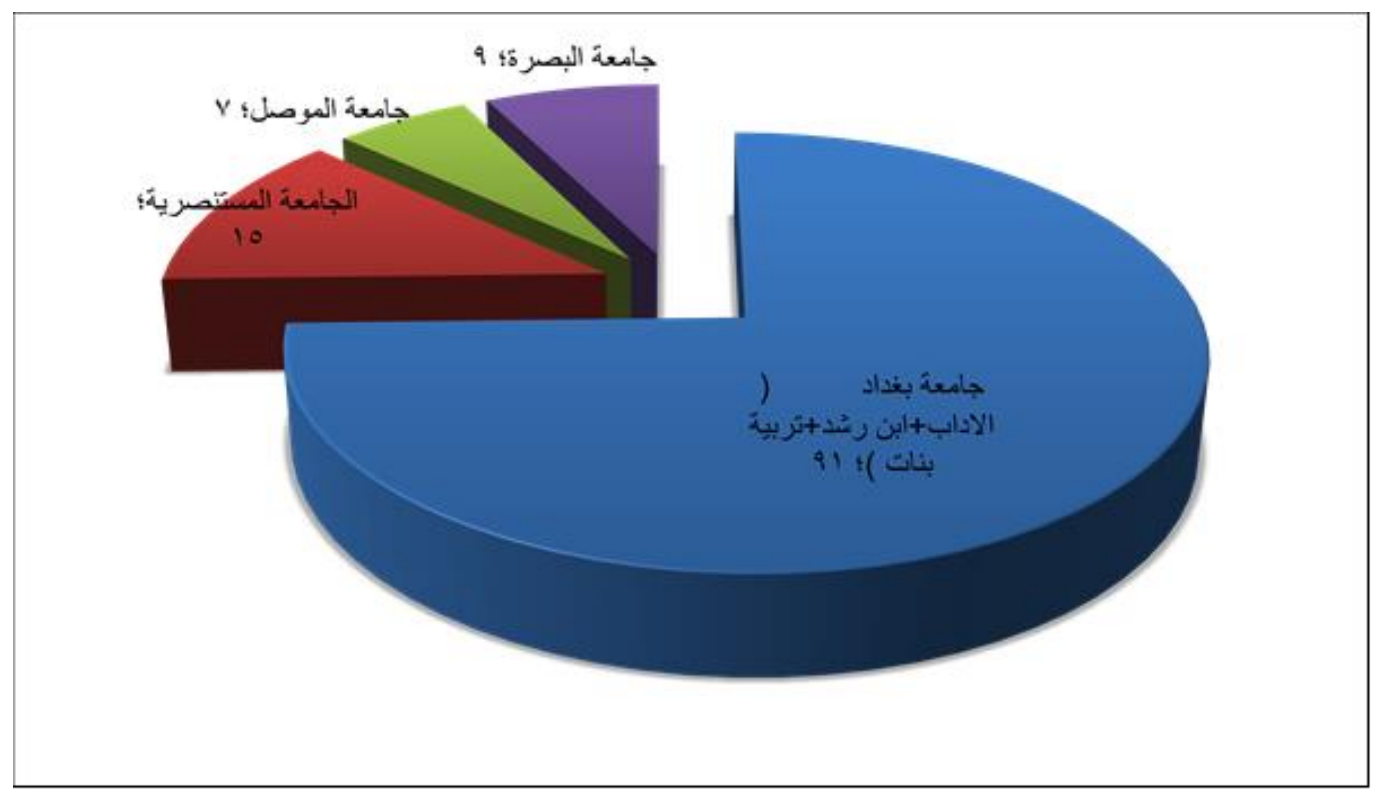

المصدر : من عمل الباحث اعتمادا على بيانات جدول (1)

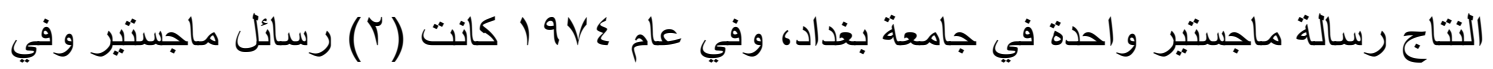

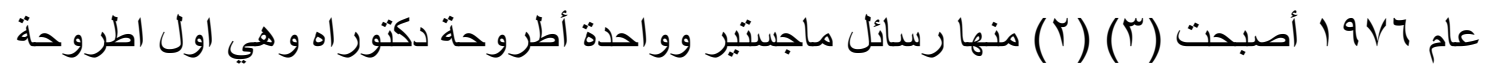

\section{通PYY 道}

جامعة البصرة؛ 9 
في العراق في جغرافية المدن، وهكا ارتفع النتاج في بقية الجامعات فكانت أول الاطاريح في

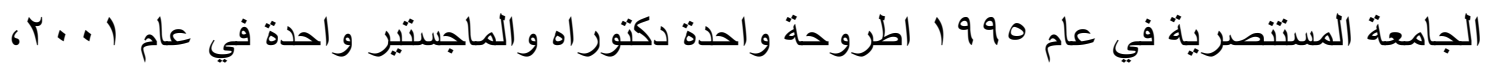

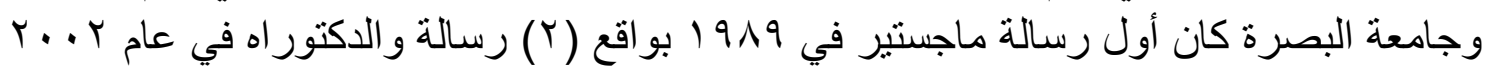
بو اقع اطروحة دكتور اه واحدة، وجامعة الموصل في عام • 99 اول اول رسالة ماجستير و الدكتور اه

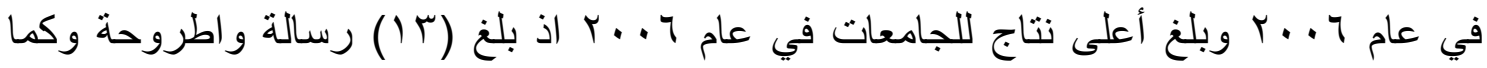

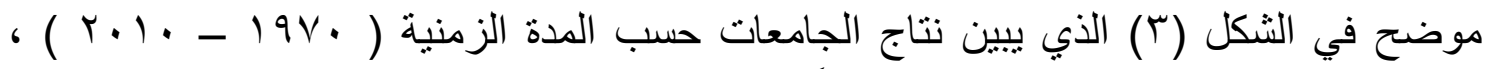

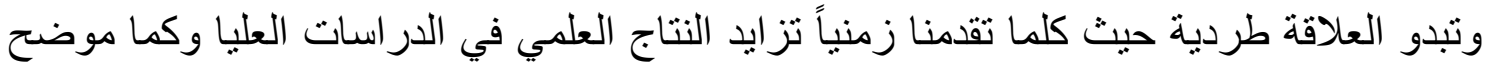
في الثكل (ع) الذي يبين التصرف الخطي المنزايد لنتاج الجامعات من رسائل واطاريح

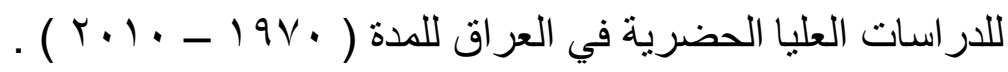

ومن هنا نلاحظ أنه يوجد نتاج كمي للار اسات الحضرية وذلك لتزايد اعداد الطلبة الذين

يدرسون الماجستير و الدكتور اه في جغر افية المدن و للتطور الذي شهدنه المدن ، وهذا مؤشر جيد

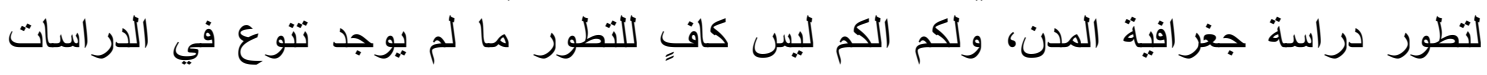
الحضرية في العراق.

شكل (r) النتـــاج الكلي للرسائل والاطاريح في الدراسات الحضرية للجامعات العراقية للمدة (

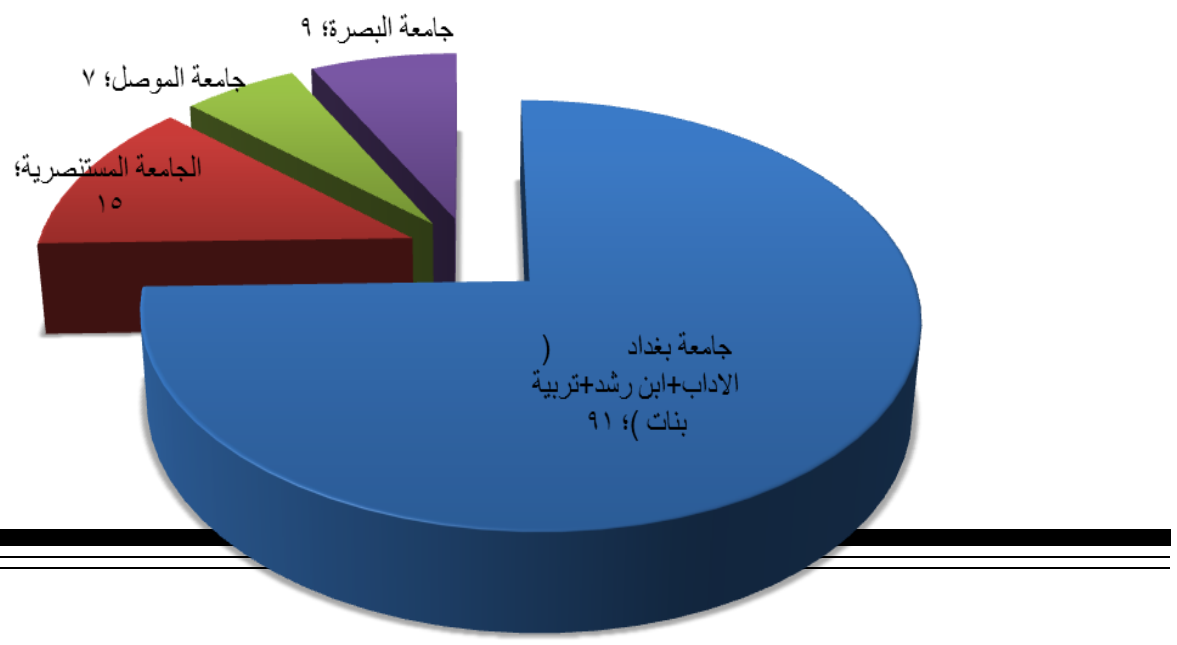


شكل (؛) التصرف الخطي المتزايد للنتــاج الكلي للرسائل والاطاريح في الاراسات

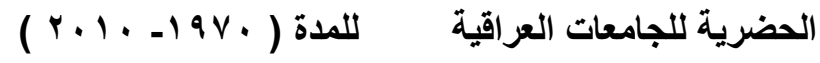

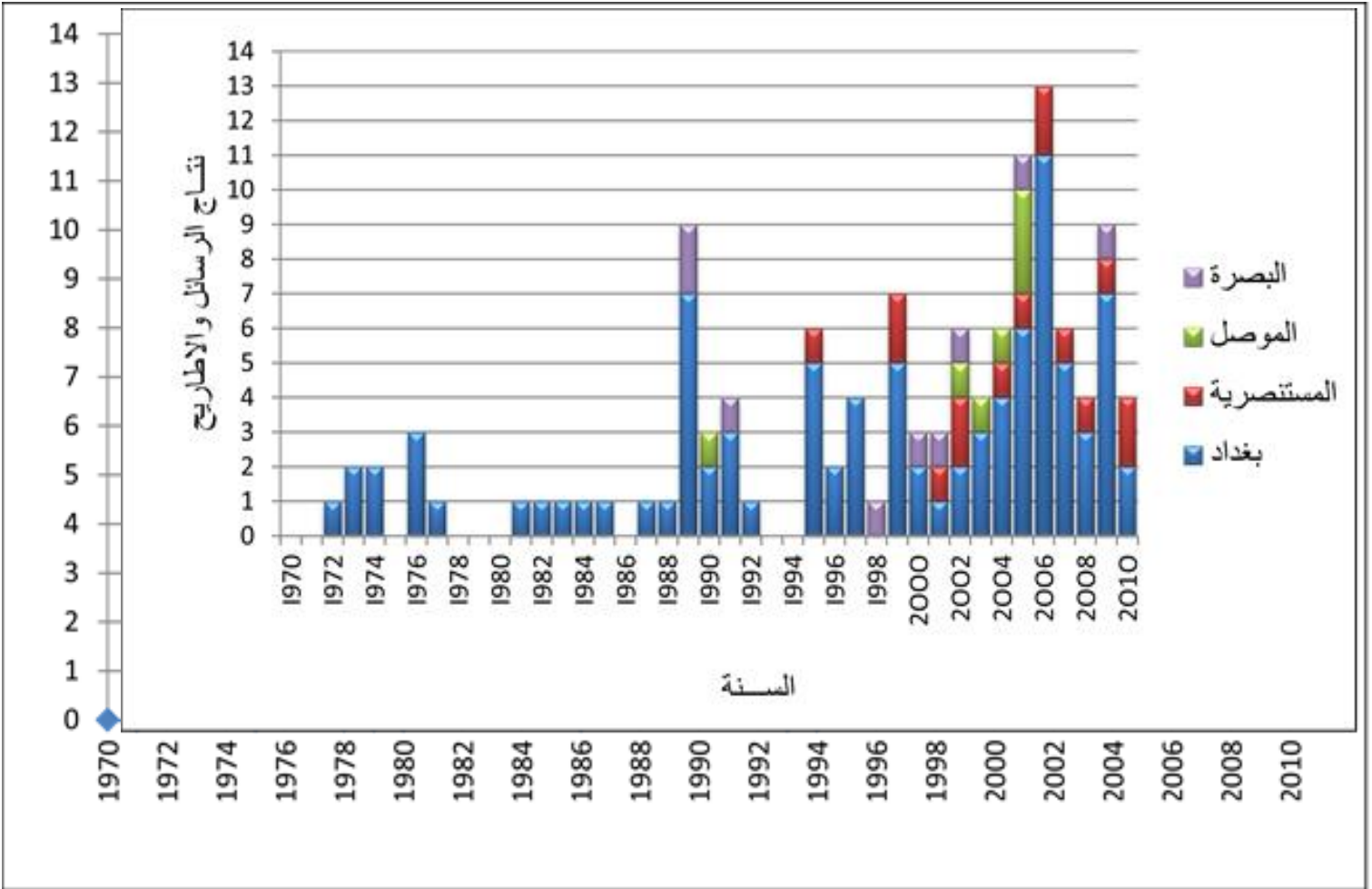

المصدر : من عمل الباحث اعتمادا على بيانات جدول ( 1 ).

ثالثا :- التغير النوعي للاراسات الحضرية في العراق

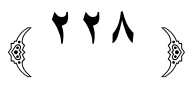


الجغر افية هي در اسة التتوع بأعتباره مصدر للوحدة وهو مبدأ من مبادئ الجغر افية (الكلاسيكية)

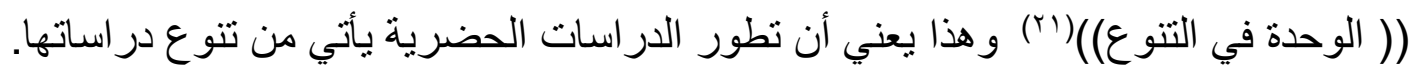

ولدراسة التغير النوعي للار اسات الحضرية في العراق لا بد من الاشارة الى بداية ظهور

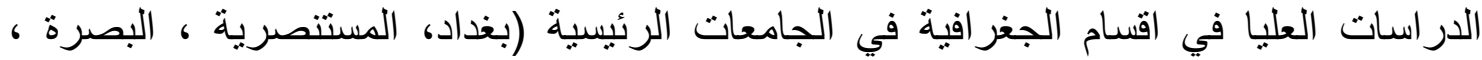
الموصل ) حتى ندرك من أين بدأ التغير حتى وقتنا هذا، وكما ذكرنا سابقاً أن جامعة بغداد هي الأي

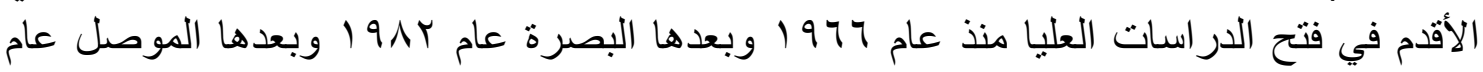

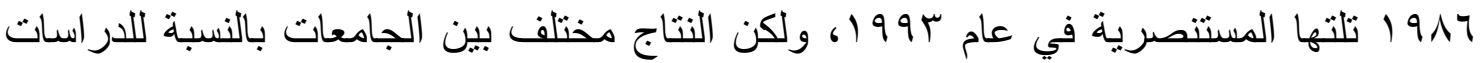

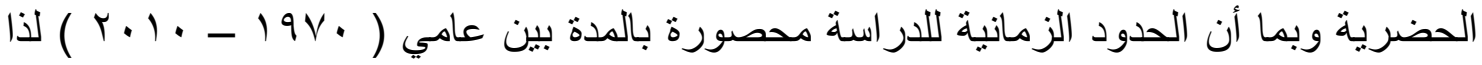
تم تقسيم التغير النوعي للدراسات الحضرية في العراق كل عثر سنوات وفقاً للمدة الزمنية المحددة لتسهيل اجر اء الدر اسة وللتمكن من بيان التنوع كالآتي:-

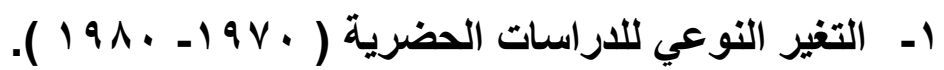

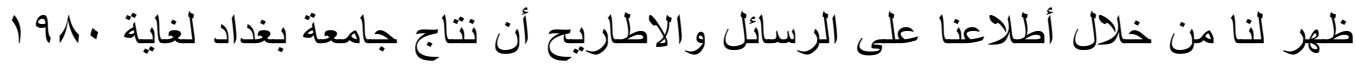

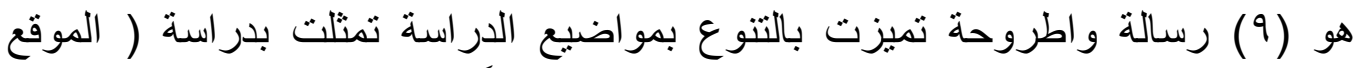

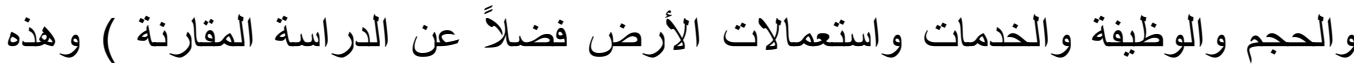

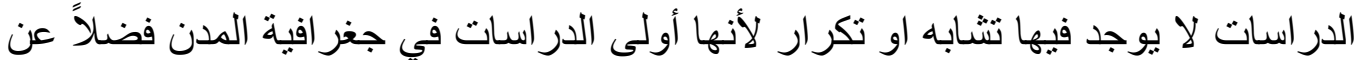

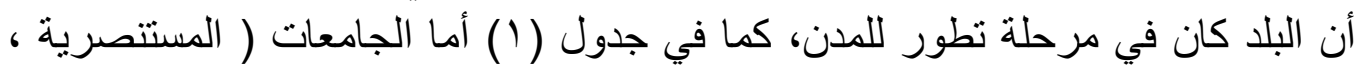

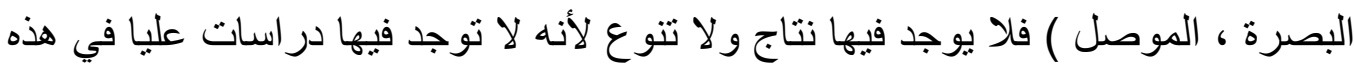

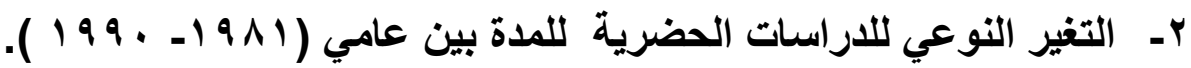

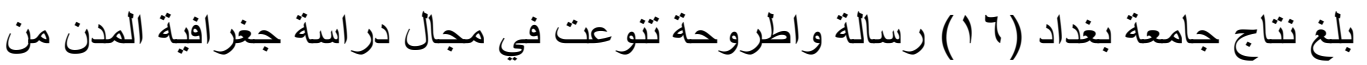
( وظائف وخدمات واستعمالات ) وظهر هذا التنوع في الدراسة الموروفولوجية و التركيب الداخلي للمدن وهذا يذل على التقدم في دراسة المدن، ولكن في الوقت نفسه

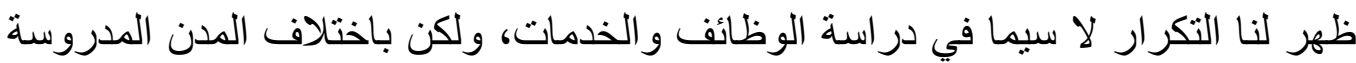

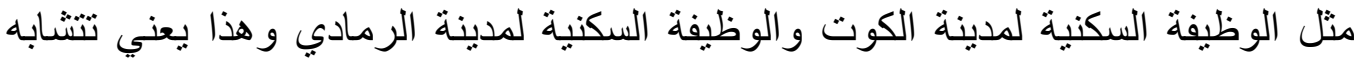

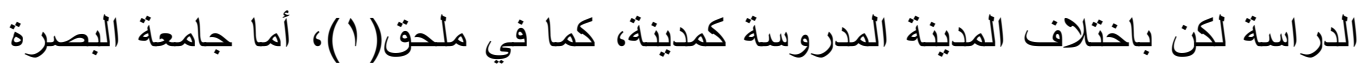

)' (Witold Wilezynski, on The Necessity of the History of Geography of Geographical Thought, paper presented at the rlst International Geographical congressin Tunis, on August i $r, r \ldots \wedge, P-\bullet$. 
فنتاجها رسالتي ماجستير في النظام الحضري ودراسة الوظائف، وجامعة الموصل

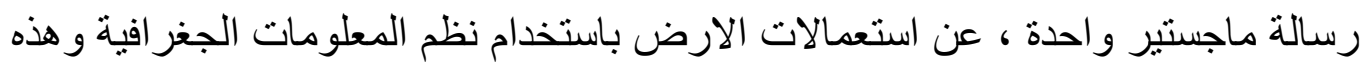

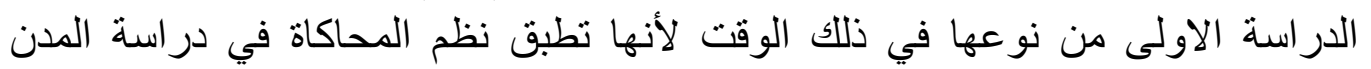

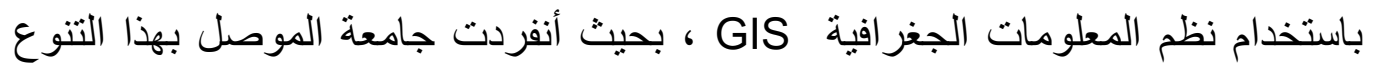
نتيجة لتوجيه الأستاذ الدكتور ابر اهيم القصاب لمثل هذه الدراسة في جغرافية المدن وبعدها انتقلت الى الجامعات الأخرى. الأنئ. أما الجامعة المستتصرية فلا يوجد فيها نتاج او تنوع لهذه المدة ، ويلاحظ لغاية عام المات

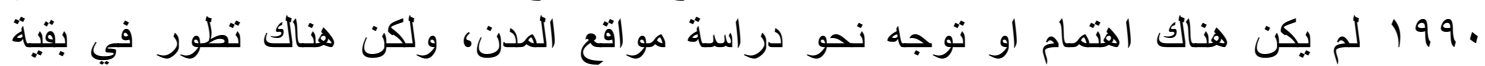
المو اضيع التي تخص جغر افية المدن.

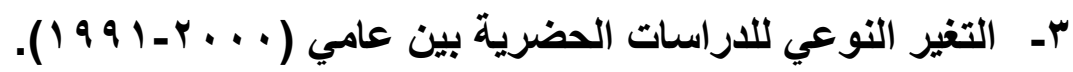

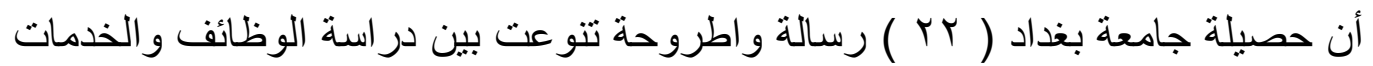
و الاستعمالات وظهر لنا دراسة ضواحي المدن الحضرية ودراسة علاقة المدينة بأقليمها ولها وذللك بسبب زيادة عدد السكان والتوسع الحاصل بالمدن، وظهور تكرار في دراسة التركيب الداخلي والتركيب الوظيفي للمدن، أما جامعة البصرة فنتاجها ثناثة لئة رسائل تحددت بدر اسة الوظائف والخدمات، وفي جامعة الموصل لا يوجد فيها نتاج خلال المدة

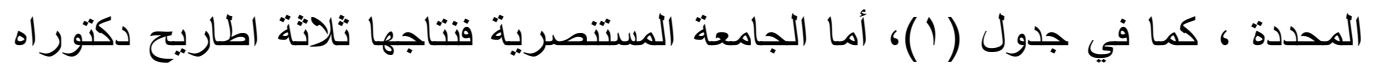
تنو عت فيها الدر اسة بين الوظائف و التحليل المكاني لاستعمالات الأرض. الإن.

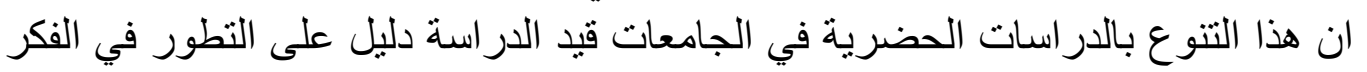

$$
\text { الجغر افي الحضري. }
$$

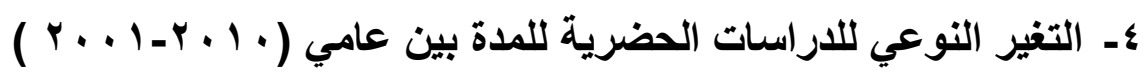

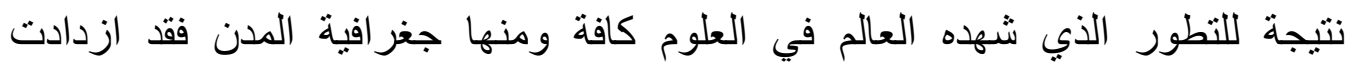

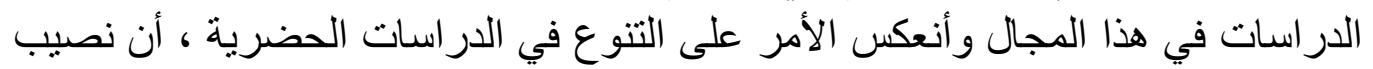

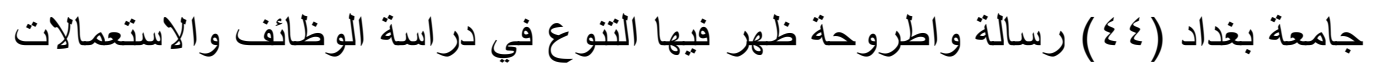

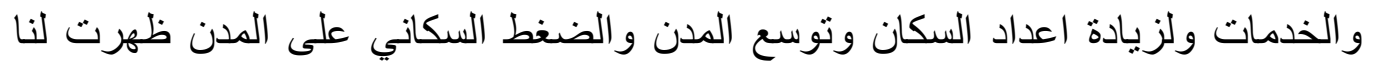

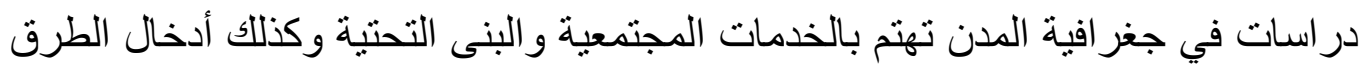

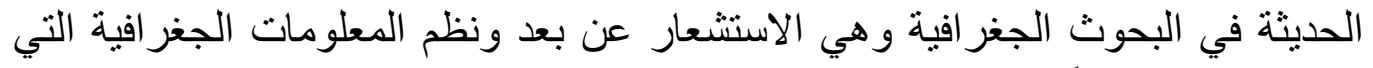

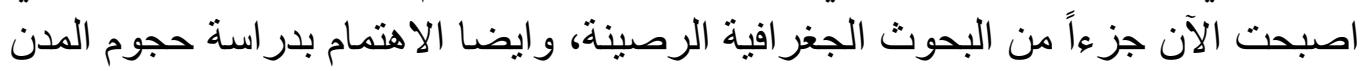

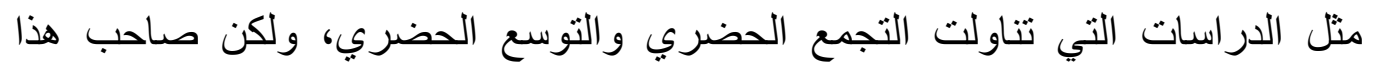

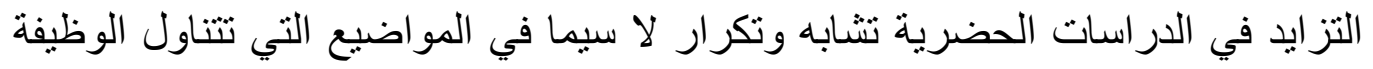
أو الوظائف والاستعمالات والخدمات، أما الجامعة المستتصرية فنتاجها (Y) (Y) رسالة واطروحة قد تنوعت بين دراسة وظائف المدن واستعمالات الأرض فيها وخدماتها لا لانها 
سيما الخدمات الصحية، وظهر تكرار في دراسة الاستعمالات والخدمات، أما جامعة

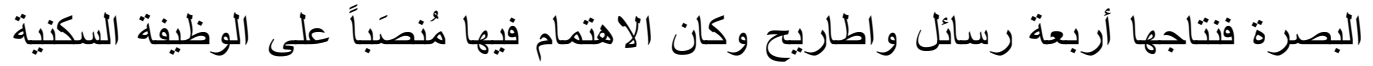

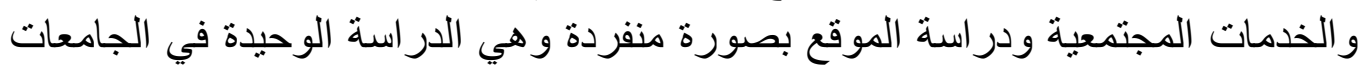
أما جامعة الموصل فكان نتاجها ستة رسائل وأطاريح تميزت جميعها بالتتوع

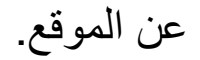
وبادخال نظم المعلومات الجغر افية في مو اضيعها، ينظر جدوله ( ).

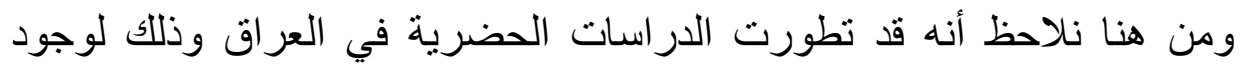

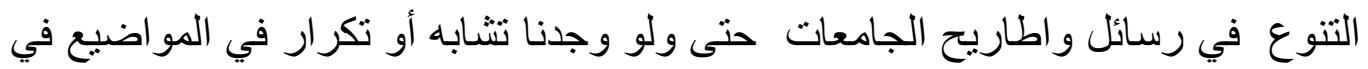

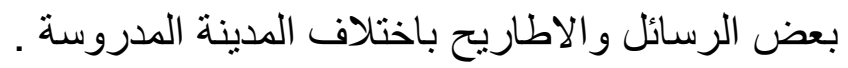

\section{رابعا : الاستتاجات والتوصيات :}

الاستتاجات : من خلال حجم العينة وهي (Y Y I ) رسالة و اطروحة موزعة على الجامعات

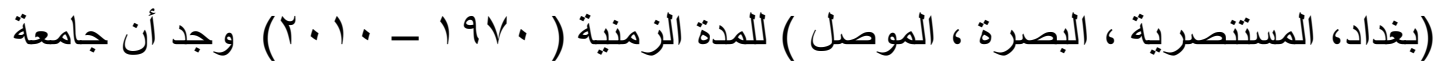

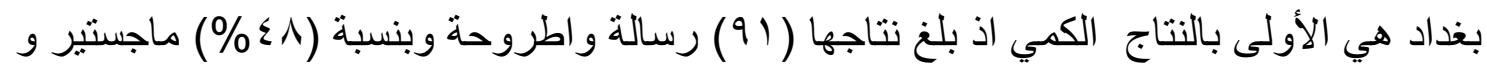

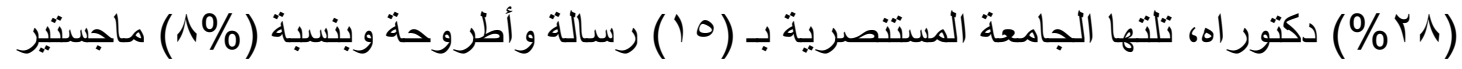

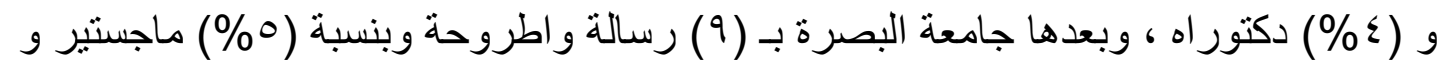

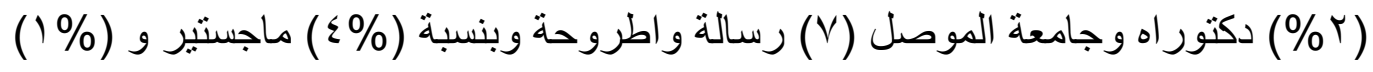

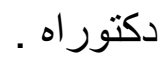

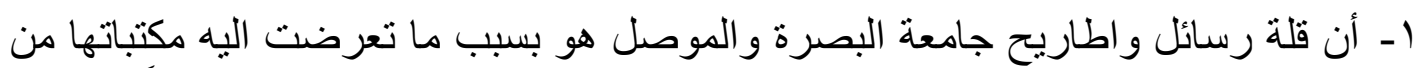

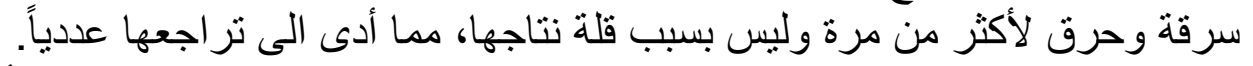

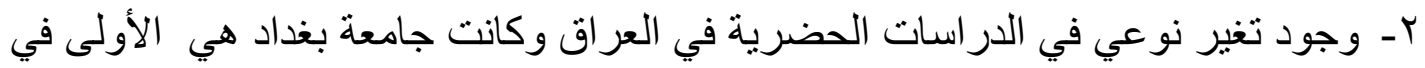

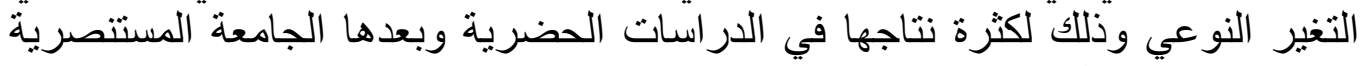

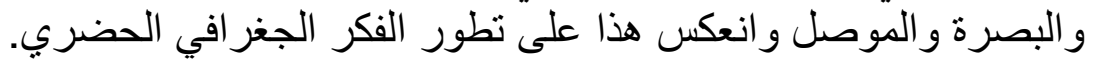

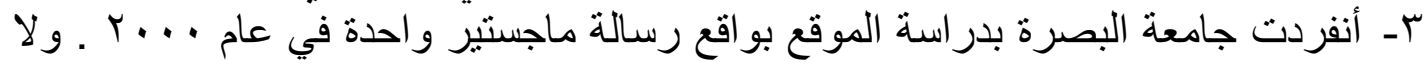

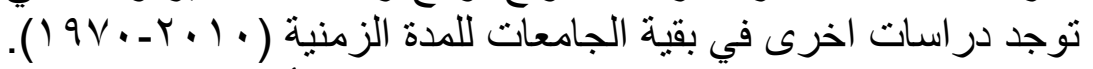

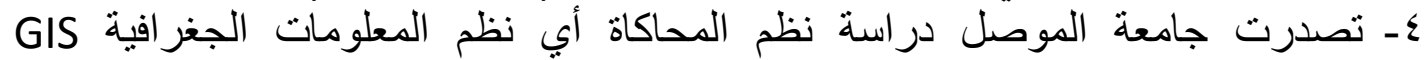

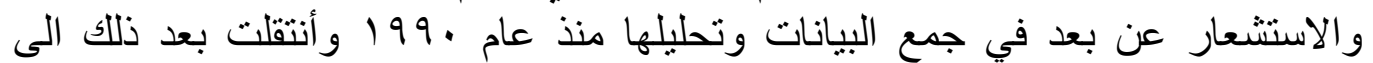

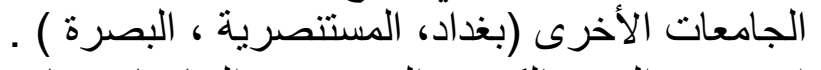

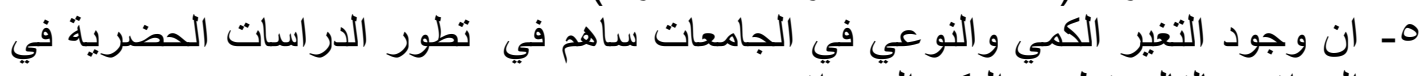
العراق وبالتالي تطوير الفكر الجغر افي . 
ا ـ الاهتمام من قبل المختصين في خطة القبول للار اسات العليا في اقسام الجغر افية بالنو عية

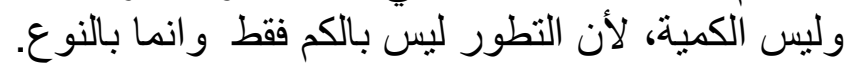

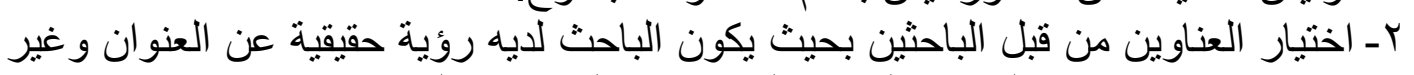

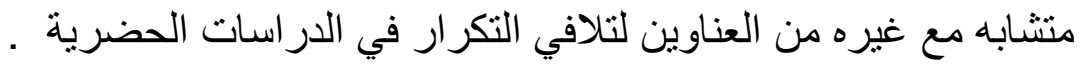

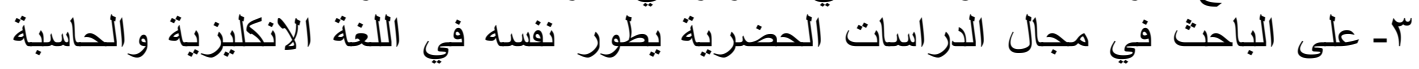

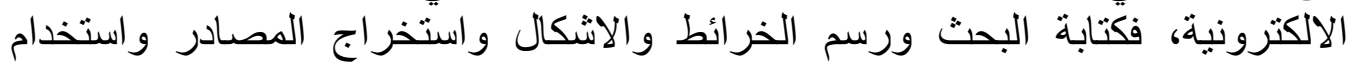

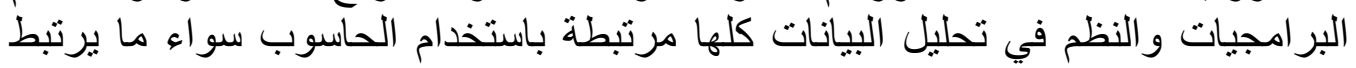

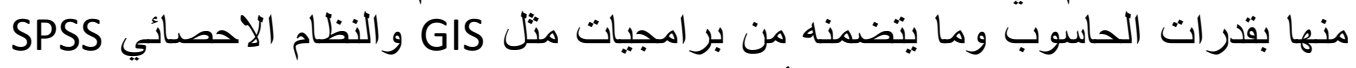

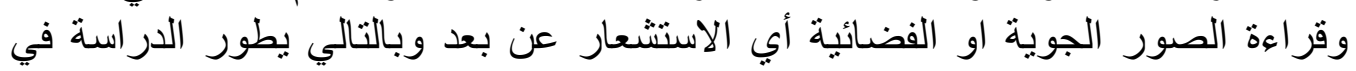
جغر افية المدن المور

\section{المصادر العربية}

r- ابو عباش ،عبد الاله ، اسحق بعقوب القطب، الاتجاهات المعاصرة في الدراسات الحضرية، طا،

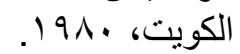

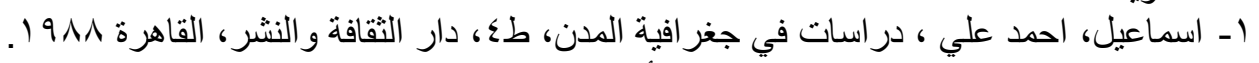

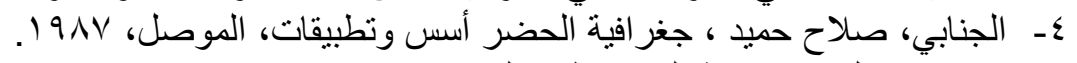

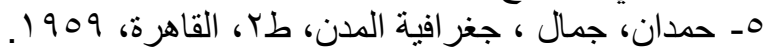

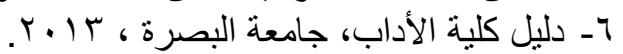

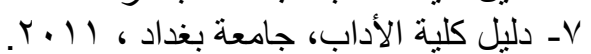

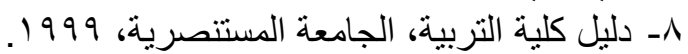

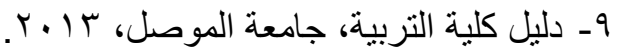

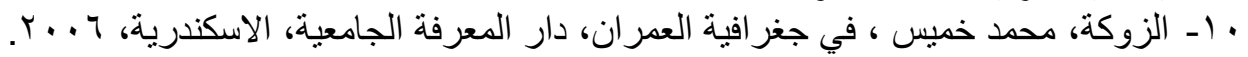
1)

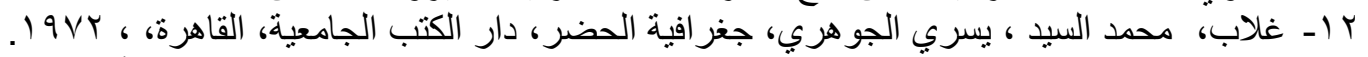

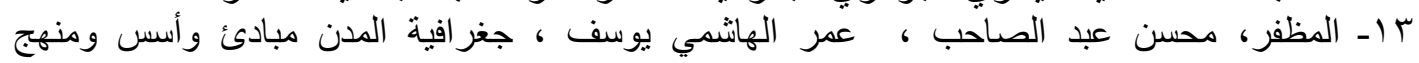

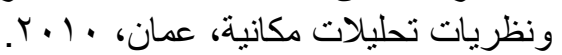

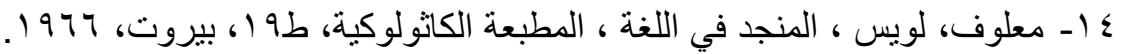

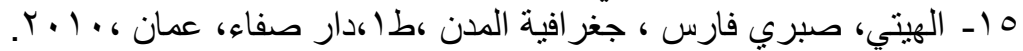

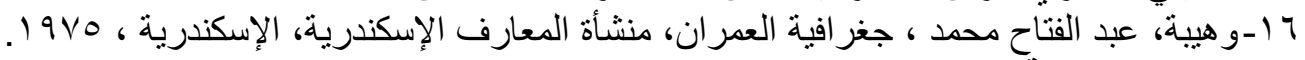
المصادر الاجنبية

1- David Kaplan, James Wheeler and Steven Hollway, Urban Geography, United States of America, 2sd ed 2009, P-6.

r- Witold Wilezynski, on The Necessity of the History of Geography of Geographical Thought, paper presented at the 31st International Geographical congressin Tunis, on August 13, 2008, P-5 . 